\title{
Critical Care Nephrology: Core Curriculum 2009
}

\author{
Kathleen D. Liu, MD, PhD, MAS \\ Division of Nephrology, Department of Medicine, Critical Care Medicine, Department of Anesthesia, \\ Box 0532, University of California, San Francisco, San Francisco, CA 94133, \\ kathleen.liu@ucsf.edu, Tel 415-476-2172, Fax 415-476-3381
}

\section{INTRODUCTION}

In the inpatient setting, a high proportion of nephrology consultations are requested for patients in the Intensive Care Unit (ICU). These patients may have acute kidney injury (AKI) or may be critically ill and have end-stage renal disease (ESRD). Thus, nephrologists need to understand recent evidence-based advances in the field of critical care, as well as areas of ongoing controversy and investigation. In this article, we summarize the diagnosis and management of shock, as well as the management of sepsis, acute lung injury/acute respiratory distress syndrome (ALI/ARDS), and fulminant hepatic failure, all of which are associated with high mortality in the critical care setting. We discuss infectious complications of critical care, including ventilator associated pneumonia and catheter related infections. Supportive care, including nutrition, insulin therapy and anemia management are reviewed. Dialysis considerations in critically ill patients are discussed. Lastly, we review the management of several life-threatening intoxications, many of which require early recognition and consideration of dialysis.

\section{SHOCK}

Definition: Absolute hypotension (e.g. systolic blood pressure less than $90 \mathrm{~mm} \mathrm{Hg}$ or mean arterial pressure less than $60 \mathrm{~mm} \mathrm{Hg}$ ) or relative hypotension (e.g. fall in systolic blood pressure of more than $40 \mathrm{~mm} \mathrm{Hg}$ ) resulting in inadequate end-organ perfusion ${ }^{1,2}$

\section{Etiologies:}

- Hypovolemic: Hemorrhage, volume depletion due to decreased fluid intake or excessive fluid losses

- Distributive: low systemic vascular resistance

$$
\begin{aligned}
& \text { - Sepsis } \\
& \text { - Anaphylaxis } \\
& \text { - Endocrine: adrenal insufficiency } \\
& \text { - Neurogenic: spinal shock }
\end{aligned}
$$

- Cardiogenic: Acute myocardial infarction, heart failure, valvular heart disease, dysrhythmias

Publisher's Disclaimer: This is a PDF file of an unedited manuscript that has been accepted for publication. As a service to our customers we are providing this early version of the manuscript. The manuscript will undergo copyediting, typesetting, and review of the resulting proof before it is published in its final citable form. Please note that during the production process errors may be discovered which could affect the content, and all legal disclaimers that apply to the journal pertain. 
- Obstructive: Extracardiac disease resulting in poor cardiac function: decreased cardiac filling (e.g. tamponade, mechanical ventilation with high positive endexpiratory pressure resulting in decreased venous return) or increased cardiac afterload (massive pulmonary embolism)

Diagnosis $^{3}$

- Echocardiography: transthoracic or transesophageal

- Invasive hemodynamic monitoring

- Central venous catheter

- Central venous pressure monitoring may be artificially high in patients on mechanical ventilation and high levels of positive end-expiratory pressure (increases intrathoracic pressure)

- Superior vena cava O2 saturation (ScVO2) as a correlate of mixed venous $\mathrm{O} 2$ saturation (which can only be measured with a pulmonary artery catheter)

$\checkmark$ Correlation with mixed venous O2 saturation somewhat controversial $^{4}$

- Pulmonary artery catheter

- Pulmonary artery occlusion pressure/pulmonary capillary wedge pressure reflects left atrial pressure in the absence of significant valvular heart disease

- Cardiac output monitoring: Fick or thermodilution

- Thermodilution cardiac output monitoring unreliable with triscupid valve disease

- Fick cardiac output monitoring uses the mixed venous oxygen saturation (obtained from the pulmonary artery) to calculate cardiac output; assumes normal $\mathrm{O} 2$ consumption

- Cardiac output, systemic vascular resistance and central venous pressure can be used to distinguish between the different types of shock

\begin{tabular}{llll}
\hline & CVP & Cardiac Output & SVR \\
Cardiogenic & High & Low & High \\
Hypovolemic & Low & Low & High \\
Distributive & Low & High & Low \\
\hline
\end{tabular}

- Pulmonary artery catheterization has not been shown to be of benefit in critically ill or surgical populations. ${ }^{5-7}$ In general, central venous pressure monitoring is sufficient. Pulmonary artery catheters may be associated with complications including infection, arrhythmias, and pulmonary artery rupture. However, in cases of mixed shock (eg, septic and cardiogenic), invasive cardiac output monitoring may be useful to tailor vasopressor therapy. Echocardiography may also be useful in the management of complex (eg, mixed etiology) shock or shock in the patient with known heart failure.

- Other methods to monitor cardiac output (partial $\mathrm{CO}_{2}$ rebreathing, pulse contour analysis) are less well validated 
- Arterial catheter

- Allows for beat-to-beat blood pressure monitoring

- Radial, femoral or dorsalis pedis sites preferred

- Perform Allen test prior to radial arterial line placement to confirm adequate collateral circulation

- Avoid ulnar and brachial arteries due to higher risk of limb ischemia

- Serum tryptase levels can be useful in anaphylaxis

Treatment

- Treat underlying cause of shock (infection, myocardial infarction)

- Volume resuscitation for hypovolemia

- Data does not support use of colloids (albumin, hextend, hydroxyethyl starch) over isotonic crystalloid solutions 8,9

- In patients with sepsis, hydroxyethyl starch administration has been associated with an increased incidence of acute kidney injury and should be avoided $^{10}$

- $\quad$ Vasoactive agents (Table 1$)^{2}$

- Vasopressors increase vascular tone, which in turn increases mean arterial pressure

- Inotropes increase cardiac contractility, and therefore cardiac output

- Commonly used medications include:

- Phenylephrine (neosynephrine): pure $\alpha$ agonist

- Dopamine: Dopamine receptor, $\beta$ and $\alpha$ agonist (dosedependent)

- Dobutamine: $\beta 1$ and $\beta 2$ agonist, use can be associated with hypotension; often used to increase cardiac output in cardiogenic shock due to congestive heart failure

- Epinephrine: $\beta 1>\alpha 1, \beta 2$ receptor agonist

- Norepinephrine (Levophed): $\alpha 1$ and $\beta 1$ agonist, associated with less tachycardia than epinephrine

- Vasopressin: Has been used as a second line pressor for refractory septic shock; use can be associated with significant mesenteric ischemia

- Milrinone/amrinone: Phosphodiesterase inhibitors with inotropic and vasodilatory effects; used along with dobutamine for the treatment of cardiogenic shock in the setting of congestive heart failure

- Early goal directed therapy for sepsis (see below)

- Corticosteroids for adrenal insufficiency (see below)

- Anaphylaxis: Epinephrine, H1 and H2 blockers, steroids

- Supportive care: Intubation and mechanical ventilation if needed 


\section{SEPSIS}

Diagnosis $^{11}$

- Systemic Inflammatory Response Syndrome (SIRS): Characterized by the presence of (1) temperature $>38^{\circ} \mathrm{C}$ or $<36^{\circ} \mathrm{C}$ (2) heart rate $>90$ beats/minute (3) respiratory rate $>20$ breaths/minute or the need for support with mechanical ventilation (4) white blood cell count $>12,000$ cells $/ \mathrm{mm}^{3}$ or $<4000$ cells $/ \mathrm{mm}^{3}$

- Sepsis: Suspected or documented infection in association with 2 or more of the SIRS criteria

- Severe sepsis: Sepsis with acute organ dysfunction

- Septic shock: Severe sepsis with hypotension despite adequate fluid resuscitation Prognosis 12

- Approximately 750,000 cases/year in the United States, resulting in approximately 200,000 deaths

- Mortality rate approximately $30-40 \%$, but higher in sicker populations

- Major risk factor for acute kidney injury

Treatment ${ }^{11}$

- Appropriate broad spectrum antibiotics and control of source of infection (e.g. debridement, removal of infected catheter)

- Volume resuscitation

- Vasopressors as needed

- Data supporting choice of first vasopressor limited

- Norepinephrine/levophed may be reasonable, since it will increase systemic vascular resistance and increase cardiac output ${ }^{13}$

- A recent clinical trial does not support the use of vasopressin as a first-line agent in combination with norepinephrine (VASST) ${ }^{14}$

- Early goal directed therapy: Refers to the combination of volume resuscitation/ vasopressors and inotropes/transfusion guided by central venous pressure (target CVP 8-12 $\mathrm{mm} \mathrm{Hg}$ ), arterial blood pressure (MAP > $65 \mathrm{~mm} \mathrm{Hg}$ ), superior vena cava oxygen saturation $(\mathrm{ScVO} 2>70 \%)$ and evidence of end-organ perfusion (urine output $>0.5$ $\mathrm{cc} / \mathrm{kg} / \mathrm{hour}$ )

- A single center randomized clinical trial showed mortality benefit with early institution of these interventions (within 6 hours of diagnosis) ${ }^{15}$

- A multicenter clinical trial (PROCESS) is ongoing to confirm the results of the initial study and to try to better correlate these interventions with benefit

- Activated protein $\mathrm{C}$ was shown to have mortality benefit for severe sepsis with APACHE II score $\geq 25$ in a large, randomized, multicenter clinical trial ${ }^{16}$

- Activated protein $\mathrm{C}$ has not been shown to be of benefit in children or in less critically ill adults 17,18

- A clinical trial in critically ill adults with refractory shock (PROWESSSHOCK) is ongoing 19 
- Role of steroids for relative adrenal insufficiency remains controversial ${ }^{20}$

- Diagnosis of relative adrenal insufficiency should be considered with refractory shock after volume resuscitiation

- Both basal cortisol level and response to high-dose adrenocorticotrophic hormone (ACTH) stimulation test have been used to define adrenal insufficiency in the critically ill ${ }^{21}$, although criteria for adrenal insufficiency remain controversial

- Annane et al demonstrated a mortality benefit with hydrocortisone/ fludrocortisone treatment for 7 days in patients with relative adrenal insufficiency and early septic shock in a multicenter, placebo controlled randomized clinical trial ${ }^{22}$

- However, in a subsequent multicenter, placebo controlled randomized clinical trial, low dose hydrocortisone therapy did not improve survival in patients with septic shock 23

- Treatment with hydrocortisone was associated with a shorter time on vasopressors but also with an increase in new sepsis and new septic shock

- Differing results may be attributable to differences in duration of septic shock, severity of illness, steroid administration (patients in Annane study randomized earlier, had higher severity of illness scores, received fludrocortisone and hydrocortisone)

- In both studies, patients were randomized after the ACTH stimulation test but before the results were available; thus patients should be empirically treated with steroids if there is a concern for relative adrenal insufficiency, rather than waiting for the results of the stimulation test

- Other supportive care as warranted by the clinical condition: intubation and mechanical ventilation, nutrition, glycemic control

- Data for some of the Surviving Sepsis guidelines is limited

\section{ACUTE LUNG INJURY/ADULT RESPIRATORY DISTRESS SYNDROME}

Diagnosis $^{24}$

Acute onset ( $<7$ days) of

- Hypoxemia: PaO2/FiO2 < 300 for Acute Lung Injury (ALI), $<200$ for Adult Respiratory Distress Syndrome (ARDS)

- Bilateral infiltrates on chest radiograph

- No clinical evidence of left atrial hypertension

Risk factors 25

- Infection: pneumonia, sepsis

- Aspiration

- Trauma

- Transfusion 
Prognosis 26

- Mortality rate $25-40 \%$ in most recent studies

Treatment

- Lung protection with a low tidal volume ventilation strategy has mortality benefit for ALI/ARDS 27

- Tidal volume $6 \mathrm{cc} / \mathrm{kg}$ ideal body weight (versus $12 \mathrm{cc} / \mathrm{kg}$ ideal body weight)

- Ideal body weight: $50+2.3 *$ (height in inches -60 ) for men, $45.5+2.3 *$ (height in inches -60 ) for women

- Plateau pressure $<30 \mathrm{~mm} \mathrm{H2O}$

- Goal PaO2 55-80 mm Hg

- Target $\mathrm{pH} 7.30-7.45$

$\checkmark$ For moderate acidosis ( $\mathrm{pH} 7.15-7.30)$, can increase respiratory rate (not to exceed 35) until $\mathrm{pH} 7.35$ or $\mathrm{PaCo} 2<25$

- For severe acidosis $(\mathrm{pH}<7.15)$, can increase respiratory rate (not to exceed 35), increase tidal volume, or administer intravenous bicarbonate

- Permissive hypercapnia/respiratory acidosis may be problematic in patients with concomitant acute kidney injury or chronic kidney disease who may have concurrent metabolic acidosis 28

- A fluid conservative management strategy increases ventilator free days in patients with ALI/ARDS 29

- Patients with ESRD or AKI requiring dialysis at the time of study enrollment were excluded from the fluid management study

- The fluid conservative management strategy was not associated with an increased requirement for dialysis

- Patients in the fluid conservative group received diuretics to achieve a target CVP of 4-8 $\mathrm{mm} \mathrm{Hg}$ or pulmonary artery occlusion pressure of 8-12 $\mathrm{mm} \mathrm{Hg}$, provided that they (1) were out of shock for 12 hours, (2) had effective circulation based on cardiac index or physical examination, and (3) were not oliguric as defined by urine output of less than $0.5 \mathrm{cc} / \mathrm{kg} / \mathrm{hour}$

- Higher levels of positive end-expiratory pressure does not appear to have mortality benefit for patients with $\mathrm{ALI}^{30-32}$

- $\quad$ Rescue therapies include

- Extracorporeal membrane oxygenation (ECMO)

- High frequency ventilation

- Partial liquid ventilation with a perflurocarbon

- Inhaled nitric oxide

- Prostacyclin

- Animal studies suggest that injurious mechanical ventilation (eg, high tidal volume) and lung injury can lead to acute kidney injury, $33-35$ although the molecular 
mechanisms have not been fully elucidated. Similarly, acute kidney injury may lead to or exacerbate existing lung injury in animal models.

\section{VENTILATOR ASSOCIATED PNEUMONIA36}

- Clinical suspicion of infection: New fevers, leukocytosis or purulent respiratory secretions, worsening respiratory failure/increased ventilator support

- Culture: Gold standard methods remain unclear

- Many ways to obtain culture specimens, including quantitative methods such as bronchoalveolar lavage and protected specimen brush, as well as nonquantative cultures and endotracheal aspirates

- Although bronchoalveolar lavage and protected brush specimen with quantitative cultures may allow for more rapid antibiotic-de-escalation, superiority to nonquantitative methods is not clear $37-39$

- Appropriate empiric initial antibiotic therapy is key: antibiotics should be tailored to known local antimicrobial resistance patterns

- Patients with ventilator associated pneumonia are at high risk for sepsis and associated acute kidney injury

\section{CATHETER RELATED INFECTIONS}

Definitions 40

- Catheter colonization: Presence of bacteria or fungi in a quantitative or semiquantitative culture of catheter material but without signs of local or systemic infection. Microorganisms grow in a bio-film that coats the surface of the catheter

- Exit site/insertion site infection: Erythema, tenderness, induration or purulence at the site where the catheter exits the skin

- Tunnel infection: Erythema, tenderness, induration or purulence in the tract where a venous catheter is tunneled under the skin

- Catheter related blood stream infection: Bacteremia in the presence of positive cultures from the catheter itself (see Diagnosis section)

Incidence

- Catheter related blood stream infections are more common with non-tunneled than with tunneled central lines

- Major risk factors for infection include duration of catheter use, number of catheter lumens (multilumen catheters carry a higher risk of infection), poor technique at the time of catheter insertion, use of total parenteral nutritition 41

- Although subclavian catheters are generally associated with a lower risk of infections compared to internal jugular and femoral catheters, these should be avoided in patients with acute kidney injury or end-stage renal disease due to the risk of subclavian stenosis.

- While the internal jugular site is generally thought to be associated with less risk of infection than the femoral site, a recent randomized clinical trial suggests that the risk of infection is similar with nontunnelled femoral and internal jugular dialysis catheters in critically ill, immobilized patients. ${ }^{42}$ However, in patients in the highest tertile of body mass index (BMI > 28.4), femoral lines were associated with an increased risk 
of infection compared to internal jugular lines. Furthermore, these results cannot be generalized to mobile, noncritically ill individuals.

Diagnosis 43

- Differential time to positivity: If a blood sample drawn from the catheter is positive more than 2 hours before the peripheral blood culture, this is highly suggestive of catheter related blood stream infection

- Quantitative blood cultures: If a blood sample drawn through the catheter has a higher concentration ( $\geq 5: 1$ ratio) of microrganisms than the peripheral blood culture, this is highly suggestive of catheter related blood stream infection

- Quantitative culture of catheter segment or catheter tip: Requires removal of central venous catheter

Treatment ${ }^{44}$

- Empiric broad spectrum antibiotics; staphylococci are common pathogen

- Removal of central venous catheter; however, this decision will depend on (1) ongoing need for central venous access (2) ability to replace the catheter at another site (3) clinical status of the patient (4) type of infection/pathogen

- Indications for catheter removal include: septic shock, presence of a tunnel infection, polymicrobial bacteremia, gram negative rod bacteremia, fungemia, evidence of distant infection (abscesses, endocarditis), and failure to respond to antibiotic therapy

\section{NUTRITION/TPN}

- Patients who are critically ill are frequently hypermetabolic/hypercatabolic and therefore are at increased risk for nutritional complications 45

- Calorie requirements can be estimated using predictive equations (Harris-Benedict or Mifflin-St Jeor for obesity) or measured using indirect calorimetry (in which $\mathrm{O} 2$ consumption and $\mathrm{CO} 2$ generation are measured in expired gas and used to calculate resting energy expenditure and the respiratory quotient)

- Indirect calorimetry is less accurate as oxygen requirements increase and is generally not useful when the patient requires a fraction of inspired $\mathrm{O} 2$ of more than 0.60

- Indirect calorimetry also allows for calculation of the respiratory quotient $(\mathrm{RQ})$; a high RQ $(\geq 1.0)$ suggests overfeeding (of either total calories or carbohydrates) or a hypermetabolic state

- Nitrogen balance can be used to determine whether the provision of nutrition therapy (particularly protein) is adequate

- Protein requirements of patients with acute kidney injury will vary based on the underlying cause of AKI and the type of renal support provided (both intermittent hemodialysis and continuous renal replacement therapy associated with ongoing protein losses) 46

- Patients on continuous renal replacement therapy (CRRT) will likely require at least $1.6-1.8 \mathrm{~g} / \mathrm{kg} /$ day of amino acids and in some studies have received up to $2.5 \mathrm{~g} / \mathrm{kg} / \mathrm{day}$ without complications

- Serum markers for nutritional adequacy in the critically ill remain controversial ${ }^{45}$ 
- Although serum albumin is a valuable prognostic indicator of morbidity and mortality, serum albumin levels decrease with metabolic stress as well as with specific disease states that are common in the ICU such as liver failure

- Transferrin, prealbumin, and retinol binding protein may be superior markers of nutritional status; however, in critical illness, synthesis of these proteins may decrease due to preferential production of acute phase reactants (i.e., $\mathrm{C}$ reactive protein)

- Prealbumin may be falsely elevated in patients with kidney failure due to reduced clearance and in patients on high-dose steroids

- Trend of prealbumin and C-reactive protein may be more useful than absolute values to follow response to nutrition therapy

- In an observational cohort study, critically ill patients with acute kidney injury did not have significantly more major gastrointestinal complications (vomiting, diarrhea, abdominal distention) nor more infectious complications (aspiration pneumonia) ${ }^{47}$

- Total parenteral nutrition is associated with an increased risk of infection and should only be used if efforts to provide enteral nutrition have failed or if the patient has a strict contraindication to enteral feeding

\section{INTENSIVE INSULIN THERAPY}

- A large, randomized clinical trial of surgical patients demonstrated mortality benefit and decreased length of ICU stay in patients who received intensive insulin therapy (target blood glucose 80 to $110 \mathrm{mg} / \mathrm{dL}[4.4-6.1 \mathrm{mmol} / \mathrm{L}])^{48}$

- A subsequent randomized clinical trial of medical patients did not show the same mortality benefit ${ }^{49}$

- However, patients who had longer ICU stays (defined as 3 or more days) did have decreased in-hospital and ICU mortality with intensive insulin therapy

- Intensive insulin therapy is associated with an increased incidence of severe hypoglycemia ${ }^{50}$

- It remains unclear if the benefit is from glycemic control or a direct effect of the insulin itself

- A pooled analysis of the large medical and surgical clinical trials suggested that patients with better glycemic control had lower mortality rates; however, it is unclear if this was as a result of the improved glycemic control or due to differences in severity of illness 51

- Similarly, a pooled analysis of the two large clinical trials and a meta-analysis suggest that intensive insulin therapy has a renoprotective effect 52,53

- However, a recent meta-analysis of 29 clinical trials (total of 8432 patients) did not demonstrate a difference in mortality or need for dialysis between patients randomized to tight versus usual glucose control. ${ }^{54}$ There was a decreased incidence of bacteremia and a marked increase in the incidence of hypoglycemia (glucose $<40 \mathrm{mg} / \mathrm{dL}[2.2$ $\mathrm{mmol} / \mathrm{L}]$ ) in the tight control group. Of note, the target glucose level in the tight control group varied across these studies from less than $100 \mathrm{mg} / \mathrm{dL}$ to less than $144 \mathrm{mg} / \mathrm{dL}$ $(<5.6-<8.0 \mathrm{mmol} / \mathrm{L})$.

- Thus, the optimum target glucose in critically ill patients remains unclear at present. 


\section{ANEMIA MANAGEMENT}

Target hemoglobin in critically ill patients

- A large, randomized clinical trial suggested that a restrictive transfusion strategy (transfusions only when the hemoglobin concentration fell below $7 \mathrm{~g} / \mathrm{dL}$ ) was safe and associated with a trend towards improved clinical outcomes when compared to a liberal transfusion strategy (transfusions when the hemoglobin concentration fell below $10 \mathrm{~g} / \mathrm{dL})^{55}$

- Of note, patients with chronic anemia (hemoglobin $<9 \mathrm{~g} / \mathrm{dL}$ ) and patients with active bleeding were excluded. In addition, the authors note that the results may be less applicable to patients with active myocardial ischemia, since a higher proportion of these patients were not enrolled in the trial because of refusal on the part of the treating physician to allow study participation.

Role of erythropoietin therapy in critically ill patients

- In a recent placebo controlled, randomized clinical trial, recombinant erythropoietin did not decrease the number of transfusions needed or the proportion of patients transfused ${ }^{56}$ Erythropoietin therapy was associated with an increased number of thrombotic events

- Given recent findings of significant complications associated with erythropoeisisstimulating agents in clinical trials of chronic kidney disease and oncology patients, 57,58 use in the critical care setting cannot be recommended at this time in the absence of kidney disease

\section{DIALYSIS CONSIDERATIONS}

Modality

- Intermittent dialysis and continuous renal replacement therapy can be considered equivalent modalities for the treatment of patients with $\mathrm{AKI}^{59,60}$

- There may be a subset of patients who are critically ill with refractory hypotension or elevated intracranial pressure (e.g. patients with fulminant hepatic failure) in whom CRRT is preferable

- CRRT: continuous fluid/volume management and slow clearance

- Arterio-venous (AV) and veno-venous (VV) modalities, now primarily VV modalities

- Continuous veno-venous hemofiltration $(\mathrm{CVVH})$ : convective clearance

- Continuous veno-venous hemodialysis (CVVHD): diffusive clearance

- Continuous veno-venous hemodiafiltration (CVVHDF): convective and diffusive clearance

- CRRT may necessitate anticoagulation to prolong the half life of the filter

- Anticoagulation typically administered pre-filter to minimize systemic anticoagulation

- Heparin and citrate are most common types of therapy 
- Citrate chelates calcium, a necessary cofactor in the coagulation cascade

- Major risk of citrate anticoagulation is hypocalcemia

- $\quad$ Can also be associated with metabolic alkalosis ( 1 molecule of citrate is converted to 3 molecules of bicarbonate)

- Drug dosing: In general, medications should be dosed for a creatinine clearance of 10-50; if possible, follow drug levels to optimize dosing

- Slow, low efficiency dialysis (SLED): 8-12 hours/treatment, 6 treatments/week hybrid technique with improved hemodynamic tolerance

Access

- $\quad$ For critically ill ESRD patients, continuous renal replacement therapy modalities require placement of a temporary or tunneled catheter

Membrane

- $\quad$ Biocompatible membranes are in more common use and may be associated with improved survival and shorter time to renal recovery 61

- Cuprophane membranes can lead to complement activation and infiltration of the kidneys by inflammatory cells, including neutrophils, which may increase renal injury and thereby delay renal recovery

Dose

- $\quad$ Recent large, multicenter randomized clinical trial (ATN study) suggested that there was no benefit with more intensive dialysis (CVVHDF with effluent flow rate of 35 $\mathrm{cc} / \mathrm{kg} /$ hour or intermittent hemodialysis 6 times/week with Kt/V of 1.2/session) compared to less intensive dialysis (CVVHDF with effluent flow rate of $20 \mathrm{cc} / \mathrm{kg}$ / hour or three times/week intermittent hemodialysis) 62

- Patients with chronic kidney disease (defined as a creatinine $>2.0 \mathrm{mg} / \mathrm{dL}$ $(177 \mu \mathrm{mol} / \mathrm{L})$ in men and $1.5 \mathrm{mg} / \mathrm{dL}[133 \mu \mathrm{mol} / \mathrm{L}]$ in women were excluded $)$

- These results are supported by a large, single center study comparing two doses of CRRT; 63 a multicenter study of two doses of CVVHDF is ongoing

- In contrast, single center clinical trials suggested mortality benefit with higher doses of CVVH and intermittent dialysis

- For the CRRT study, there may have been differences in the characteristics of patients treated and treatment characteristics ${ }^{64}$ (including a higher proportion of surgical patients, fewer patients with sepsis and inclusion of patients with chronic kidney disease, as well as use of lactate-based replacement fluid and post-filter replacement fluid administration)

- For the IHD study, doses of dialysis provided per treatment were lower than in the ATN study 65

Timing

- Optimum timing of initiation of dialysis for AKI remains unclear, though observational studies have suggested potential benefit to earlier initiation of dialysis 66,67 
- A number of the critical care practices described in this article may impact the metabolic parameters that trigger the decision to initiate dialysis. ${ }^{28}$ Specifically, lowtidal volume ventilation and permissive hypercapnia may exacerbate acidemia in a patient with acute kidney injury and an associated metabolic acidosis. Early goal directed therapy may ultimately result in volume overload, and, depending on the fluid selected for resuscitation, a hyperchloremic metabolic acidosis. Steroid administration for relative adrenal insufficiency may exacerbate azotemia and volume retention. Thus, these changes in critical care practice may necessitate earlier initiation of dialysis in selected patients.

\section{FULMINANT HEPATIC FAILURE}

- Common etiologies: medications/toxins (acetaminophen, Amanita phalloides mushroom poisoning, other drug reactions), acute viral infections (hepatitis B, A), vascular causes (portal vein thrombosis, hepatic vein thrombosis = Budd-Chiari syndrome), metabolic diseases (Wilson's disease, acute fatty liver of pregnancy, Reye's syndrome), cryptogenic 68,69

- Orthotopic liver transplantation is definitive therapy

- Mortality high with supportive care alone

- Common complications include:

- Hepatic encephalopathy

- Cerebral edema: can lead to increased intracranial pressure and brainstem herniation

- Major cause of mortality in this population

- Patients with compromised kidney function may require continuous renal replacement therapy to avoid fluctuations in intracranial pressure and tight volume control (especially in setting of transfusions of large volumes of blood products)

- Acute kidney injury: altered hemodynamics, direct toxicity

- Due to large volume of blood products and cerebral edema, may require support with continuous renal replacement therapy before conventional "indications" are met ${ }^{69}$

- Coagulopathy

- Hypoglycemia

- Infection/sepsis

\section{INTOXICATIONS}

- Acetaminophen

- N-acetylcysteine

- Supportive care for fulminant hepatic failure, including metabolic acidosis (hepatocyte necrosis and inability to metabolize lactate can result in severe lactic acidosis)

- Acute kidney injury, may be direct effect of acetaminophen leading to acute tubular necrosis or hepatorenal syndrome; usually recovers spontaneously, but may require dialytic support. 
- 5-oxoprolinuria and associated metabolic acidosis may occur in susceptible individuals, even when only recommended doses of acetaminophen are administered $^{70}$

- Consider in a patient with recent acetaminophen use, unexplained metabolic acidosis, altered mental status

- N-acetylcysteine may increase glutathione levels and be of benefit

- $\quad$ Salicylates $^{71}$

- Classically presents with respiratory alkalosis and anion gap metabolic acidosis

- Symptoms include tinnitus, altered mental status, nausea/vomiting

- Activated charcoal for gut decontamination

- Glucose should be administered if the patient has altered mental status because aspirin can cause $\mathrm{CNS}_{[\mathrm{A} 2]}$ hypoglycemia, even with normal serum glucose concentrations

- Sodium bicarbonate to promote mobilization of salicylates from tissue stores to the plasma and urinary excretion

- Hemodialysis: Altered mental status, volume overload, plasma salicylate concentration $>100 \mathrm{mg} / \mathrm{dL}$

- Methanol/ethylene glycol 72,73

- Present with anion gap acidosis and osmolar gap

- Early recognition is critical

- Visual changes including blurry vision, central scotomata, blindness, retinal edema and hyperemia of the optic disk are characteristic of methanol poisoning

- Oliguria and calcium oxalate crystals in the urine are characteristic of ethylene glycol toxicity; can use UV light (Woods lamp) to look for fluorescence in the urine (fluroscein added to most antifreeze)

- Fomepizole/ethanol competitively inhibits alcohol dehydrogenase and prevents the formation of toxic metabolites (methanol is converted to formate, ethylene glycol to glycolate/glyoxylate/oxalate)

- Dialysis will remove both the alcohols and toxic metabolites

- Should not wait for confirmatory testing to initiate treatment

- Consider empiric therapy in a patient with unexplained anion gap acidosis, osmolar gap, and suspected ingestion/evidence of end-organ dysfunction

- Additional supportive care including folate/thiamine

- Lithium $^{74}$

- Presents with altered mental status, neuromuscular excitability, tremors, nausea, vomiting, seizures

- Consider dialysis based on absolute level as well as symptoms 
- Slow equilibration between intracellular and extracellular lithium may lead to plasma rebound and necessitate extended dialysis sessions ( $8-12$ hours)

- Metformin 75

- Can be associated with life-threatening lactic acidosis, in particular when used in patients with reduced kidney function or hepatic dysfunction, heart failure, prior history of lactic acidosis, or patients with ongoing hypoperfusion or hemodynamic instability

- Metformin should be held if a patient requires parenteral contrast for a CT scan for at least 48 hours post-study to ensure normal kidney function

- In patients with life threatening acidosis, dialysis will remove metformin and allow for the provision of bicarbonate to treat the acidosis

- Other toxicities to consider hemodialysis for: paraquat, isopropanol, theophylline (cleared by dialysis, but more efficiently cleared by charcoal hemoperfusion)

\section{SPECIAL ACID/BASE AND ELECTROLYTE ABNORMALITIES}

- Propofol can be associated with life-threatening metabolic acidosis, especially in children 76

- Lorazepam (Ativan) infusions contain polyethylene glycol as a carrier agent and can be associated with an anion gap acidosis 76

- Cerebral salt wasting with central nervous system disease (subarachnoid hemorrhage, post-neurosurgery) can lead to profound hyponatremia 77

- Can be differentiated from CNS-associated syndrome of inappropriate antidiuretic hormone (SIADH) by volume status: $\mathrm{CSW}_{[\mathrm{A} 3]}$ leads to hypovolemia, patients with SIADH are euvolemic

\section{Acknowledgments}

Dr Liu is supported by NIH/NCRR/OD UCSF-CTSI Grant Number KL2 RR024130

Financial Disclosure: None.

\section{References}

1. Parrillo, J. Approach to the patient with shock. In: Goldman, L.; Ausiello, D., editors. Cecil Medicine. Vol. 23. Philadelphia, PA: Saunders Elsevier; 2007.

2. Herget-Rosenthal S, Saner F, Chawla LS. Approach to hemodynamic shock and vasopressors. Clin J Am Soc Nephrol Mar;2008 3(2):546-553. [PubMed: 18256381]

3. Davison D, Junker C. Advances in critical care for the nephrologist: hemodynamic monitoring and volume management. Clin J Am Soc Nephrol Mar;2008 3(2):554-561. [PubMed: 18256382]

4. Chawla LS, Zia H, Gutierrez G, Katz NM, Seneff MG, Shah M. Lack of equivalence between central and mixed venous oxygen saturation. Chest Dec;2004 126(6):1891-1896. [PubMed: 15596689]

5. Sandham JD, Hull RD, Brant RF, et al. A randomized, controlled trial of the use of pulmonary-artery catheters in high-risk surgical patients. N Engl J Med Jan 2;2003 348(1):5-14. [PubMed: 12510037]

6. Wheeler AP, Bernard GR, Thompson BT, et al. Pulmonary-artery versus central venous catheter to guide treatment of acute lung injury. N Engl J Med May 25;2006 354(21):2213-2224. [PubMed: 16714768]

7. Richard C, Warszawski J, Anguel N, et al. Early use of the pulmonary artery catheter and outcomes in patients with shock and acute respiratory distress syndrome: a randomized controlled trial. Jama Nov 26;2003 290(20):2713-2720. [PubMed: 14645314] 
8. Finfer S, Bellomo R, Boyce N, French J, Myburgh J, Norton R. A comparison of albumin and saline for fluid resuscitation in the intensive care unit. N Engl J Med May 27;2004 350(22):2247-2256. [PubMed: 15163774]

9. Perel P, Roberts I. Colloids versus crystalloids for fluid resuscitation in critically ill patients. Cochrane Database Syst Rev 2007;17(4):CD000567. [PubMed: 17943746]

10. Brunkhorst FM, Engel C, Bloos F, et al. Intensive insulin therapy and pentastarch resuscitation in severe sepsis. N Engl J Med Jan 10;2008 358(2):125-139. [PubMed: 18184958]

11. Bone RC, Balk RA, Cerra FB, et al. Definitions for sepsis and organ failure and guidelines for the use of innovative therapies in sepsis. The ACCP/SCCM Consensus Conference Committee. American College of Chest Physicians/Society of Critical Care Medicine. Chest Jun;1992 101(6): 1644-1655. [PubMed: 1303622]

12. Angus DC, Linde-Zwirble WT, Lidicker J, Clermont G, Carcillo J, Pinsky MR. Epidemiology of severe sepsis in the United States: analysis of incidence, outcome, and associated costs of care. Crit Care Med Jul;2001 29(7):1303-1310. [PubMed: 11445675]

13. Martin C, Viviand X, Leone M, Thirion X. Effect of norepinephrine on the outcome of septic shock. Crit Care Med Aug;2000 28(8):2758-2765. [PubMed: 10966247]

14. Russell JA, Walley KR, Singer J, et al. Vasopressin versus Norepinephrine Infusion in Patients with Septic Shock. N Engl J Med February 28, 2008;2008 358(9):877-887. [PubMed: 18305265]

15. Rivers E, Nguyen B, Havstad S, et al. Early Goal-Directed Therapy in the Treatment of Severe Sepsis and Septic Shock. N Eng J Med 2001;345:1368-1377.

16. Bernard GR, Vincent JL, Laterre PF, et al. Efficacy and safety of recombinant human activated protein C for severe sepsis. N Engl J Med Mar 8;2001 344(10):699-709. [PubMed: 11236773]

17. Abraham E, Laterre PF, Garg R, et al. Drotrecogin alfa (activated) for adults with severe sepsis and a low risk of death. N Engl J Med Sep 29;2005 353(13):1332-1341. [PubMed: 16192478]

18. Nadel S, Goldstein B, Williams MD, et al. Drotrecogin alfa (activated) in children with severe sepsis: a multicentre phase III randomised controlled trial. Lancet Mar 10;2007 369(9564):836-843. [PubMed: 17350452]

19. Barie PS. "All in" for a huge pot: the PROWESS-SHOCK trial for refractory septic shock. Surg Infect (Larchmt) Oct;2007 8(5):491-494. [PubMed: 17999581]

20. Marik PE, Pastores SM, Annane D, et al. Recommendations for the diagnosis and management of corticosteroid insufficiency in critically ill adult patients: consensus statements from an international task force by the American College of Critical Care Medicine. Crit Care Med Jun;2008 36(6):19371949. [PubMed: 18496365]

21. Cooper MS, Stewart PM. Adrenal insufficiency in critical illness. J Intensive Care Med Nov-Dec; 2007 22(6):348-362. [PubMed: 18048877]

22. Annane D, Sebille V, Charpentier C, et al. Effect of treatment with low doses of hydrocortisone and fludrocortisone on mortality in patients with septic shock. Jama Aug 21;2002 288(7):862-871. [PubMed: 12186604]

23. Sprung CL, Annane D, Keh D, et al. Hydrocortisone therapy for patients with septic shock. N Engl J Med Jan 10;2008 358(2):111-124. [PubMed: 18184957]

24. Bernard GR, Artigas A, Brigham KL, et al. The American-European Consensus Conference on ARDS. Definitions, mechanisms, relevant outcomes, and clinical trial coordination. Am J Respir Crit Care Med Mar;1994 149(3 Pt 1):818-824. [PubMed: 7509706]

25. Ware LB, Matthay MA. The acute respiratory distress syndrome. N Engl J Med May 4;2000 342(18): 1334-1349. [PubMed: 10793167]

26. Liu KD, Matthay MA. Advances in critical care for the nephrologist: acute lung injury/ARDS. Clin J Am Soc Nephrol Mar;2008 3(2):578-586. [PubMed: 18199848]

27. Brower RG, Shanholtz CB, Fessler HE, et al. Prospective, randomized, controlled clinical trial comparing traditional versus reduced tidal volume ventilation in acute respiratory distress syndrome patients. Crit Care Med Aug;1999 27(8):1492-1498. [PubMed: 10470755]

28. Liu KD, Matthay MA, Chertow GM. Evolving practices in critical care and potential implications for management of acute kidney injury. Clin J Am Soc Nephrol Jul;2006 1(4):869-873. [PubMed: 17699299] 
29. Wiedemann HP, Wheeler AP, Bernard GR, et al. Comparison of two fluid-management strategies in acute lung injury. N Engl J Med Jun 15;2006 354(24):2564-2575. [PubMed: 16714767]

30. Brower R, Lanken P, MacIntyre N, et al. Higher versus lower positive end-expiratory pressures in patients with the acute respiratory distress syndrome. N Engl J Med 2004;351(4):327-336. [PubMed: 15269312]

31. Meade MO, Cook DJ, Guyatt GH, et al. Ventilation strategy using low tidal volumes, recruitment maneuvers, and high positive end-expiratory pressure for acute lung injury and acute respiratory distress syndrome: a randomized controlled trial. Jama Feb 13;2008 299(6):637-645. [PubMed: 18270352]

32. Mercat A, Richard JC, Vielle B, et al. Positive end-expiratory pressure setting in adults with acute lung injury and acute respiratory distress syndrome: a randomized controlled trial. Jama Feb 13;2008 299(6):646-655. [PubMed: 18270353]

33. Imai Y, Parodo J, Kajikawa O, et al. Injurious mechanical ventilation and end-organ epithelial cell apoptosis and organ dysfunction in an experimental model of acute respiratory distress syndrome. Jama Apr 23-30;2003 289(16):2104-2112. [PubMed: 12709468]

34. Choi WI, Quinn DA, Park KM, et al. Systemic microvascular leak in an in vivo rat model of ventilatorinduced lung injury. Am J Respir Crit Care Med Jun 15;2003 167(12):1627-1632. [PubMed: 12663326]Epub 2003 Mar 1627

35. Kuiper JW, Groeneveld AB, Slutsky AS, Plotz FB. Mechanical ventilation and acute renal failure. Crit Care Med Jun;2005 33(6):1408-1415. [PubMed: 15942363]

36. Guidelines for the management of adults with hospital-acquired, ventilator-associated, and healthcareassociated pneumonia. Am J Respir Crit Care Med Feb 15;2005 171(4):388-416. [PubMed: 15699079]

37. Shorr AF, Sherner JH, Jackson WL, Kollef MH. Invasive approaches to the diagnosis of ventilatorassociated pneumonia: a meta-analysis. Crit Care Med Jan;2005 33(1):46-53. [PubMed: 15644647]

38. Kollef MH. Diagnosis of ventilator-associated pneumonia. N Engl J Med Dec 21;2006 355(25):26912693. [PubMed: 17182995]

39. A randomized trial of diagnostic techniques for ventilator-associated pneumonia. N Engl J Med Dec 21;2006 355(25):2619-2630. [PubMed: 17182987]

40. Mermel LA, Farr BM, Sherertz RJ, et al. Guidelines for the management of intravascular catheterrelated infections. Clin Infect Dis May 1;2001 32(9):1249-1272. [PubMed: 11303260]

41. Safdar N, Kluger DM, Maki DG. A review of risk factors for catheter-related bloodstream infection caused by percutaneously inserted, noncuffed central venous catheters: implications for preventive strategies. Medicine (Baltimore) Nov;2002 81(6):466-479. [PubMed: 12441903]

42. Parienti JJ, Thirion M, Megarbane B, et al. Femoral vs jugular venous catheterization and risk of nosocomial events in adults requiring acute renal replacement therapy: a randomized controlled trial. Jama May 28;2008 299(20):2413-2422. [PubMed: 18505951]

43. Safdar N, Fine JP, Maki DG. Meta-analysis: methods for diagnosing intravascular device-related bloodstream infection. Ann Intern Med Mar 15;2005 142(6):451-466. [PubMed: 15767623]

44. Band J. Treatment of central venous catheter-related infections. Up To Date.

45. Stralovich-Romani, A.; Mahutte, C.; Luce, J. Nutritional and ethical principles in critical illness and injury. In: George, R.; Light, R.; Matthay, M.; Matthay, R., editors. Chest Medicine. Vol. 5. Philadelphia, PA: Lippincott Williams and Wilkins; 2005. p. 497-516.

46. Liu, KD.; Stralovich-Romani, A.; Chertow, GM. Nutrition Support for Adult Patients With Acute Renal Failure. In: Merritt, R., editor. American Society for Parenteral and Enteral Nutrition (ASPEN) Nutrition Support Guidelines. Silver Spring, MD: American Society for Parenteral and Enteral Nutrition; 2006. p. 281-286.

47. Fiaccadori E, Maggiore U, Giacosa R, et al. Enteral nutrition in patients with acute renal failure. Kidney Int 2004;64:999-1004. [PubMed: 14871420]

48. Van den Berghe G, Wouters P, Weekers F, et al. Intensive insulin therapy in the critically ill patient. N Eng J Med 2001;345(19):1359-1367.

49. Van den Berghe G, Wilmer A, Hermans G, et al. Intensive insulin therapy in the medical ICU. N Engl J Med Feb 2;2006 354(5):449-461. [PubMed: 16452557] 
50. Schetz MRC. Classical and alternative indications for continuous renal replacement therapy. Kidney International 1999;53(Supp 66):S129-132.

51. Van den Berghe G, Wilmer A, Milants I, et al. Intensive insulin therapy in mixed medical/surgical intensive care units: benefit versus harm. Diabetes Nov;2006 55(11):3151-3159. [PubMed: 17065355]

52. Thomas G, Rojas MC, Epstein SK, Balk EM, Liangos O, Jaber BL. Insulin therapy and acute kidney injury in critically ill patients a systematic review. Nephrol Dial Transplant Oct;2007 22(10):2849_ 2855. [PubMed: 17604310]

53. Schetz M, Vanhorebeek I, Wouters PJ, Wilmer A, Van den Berghe G. Tight blood glucose control is renoprotective in critically ill patients. J Am Soc Nephrol Mar;2008 19(3):571-578. [PubMed: 18235100]

54. Wiener RS, Wiener DC, Larson RJ. Benefits and risks of tight glucose control in critically ill adults: a meta-analysis. Jama Aug 27;2008 300(8):933-944. [PubMed: 18728267]

55. Hebert PC, Wells G, Blajchman MA, et al. A multicenter, randomized, controlled clinical trial of transfusion requirements in critical care. Transfusion Requirements in Critical Care Investigators, Canadian Critical Care Trials Group. N Engl J Med Feb 11;1999 340(6):409-417. [PubMed: 9971864]

56. Corwin HL, Gettinger A, Fabian TC, et al. Efficacy and safety of epoetin alfa in critically ill patients. N Engl J Med Sep 6;2007 357(10):965-976. [PubMed: 17804841]

57. Phrommintikul A, Haas SJ, Elsik M, Krum H. Mortality and target haemoglobin concentrations in anaemic patients with chronic kidney disease treated with erythropoietin: a meta-analysis. Lancet Feb 3;2007 369(9559):381-388. [PubMed: 17276778]

58. Bennett CL, Silver SM, Djulbegovic B, et al. Venous thromboembolism and mortality associated with recombinant erythropoietin and darbepoetin administration for the treatment of cancerassociated anemia. Jama Feb 27;2008 299(8):914-924. [PubMed: 18314434]

59. Bagshaw SM, Berthiaume LR, Delaney A, Bellomo R. Continuous versus intermittent renal replacement therapy for critically ill patients with acute kidney injury: a meta-analysis. Crit Care Med Feb;2008 36(2):610-617. [PubMed: 18216610]

60. Vinsonneau C, Camus C, Combes A, et al. Continuous venovenous haemodiafiltration versus intermittent haemodialysis for acute renal failure in patients with multiple-organ dysfunction syndrome: a multicentre randomised trial. Lancet Jul 29;2006 368(9533):379-385. [PubMed: 16876666]

61. Subramanian S, Venkataraman R, Kellum J. Influence of dialysis membranes on outcomes in acute renal failure: A meta-analysis. Kidney Int 2002;62:1819-1823. [PubMed: 12371984]

62. Palevsky PM, Zhang JH, O'Connor TZ, et al. Intensity of renal support in critically ill patients with acute kidney injury. N Engl J Med Jul 3;2008 359(1):7-20. [PubMed: 18492867]

63. Tolwani AJ, Campbell RC, Stofan BS, Lai KR, Oster RA, Wille KM. Standard versus high-dose CVVHDF for ICU-related acute renal failure. J Am Soc Nephrol Jun;2008 19(6):1233-1238. [PubMed: 18337480]

64. Ronco C, Bellomo R, Homel P, et al. Effects of different doses in continuous veno-venous haemofiltration on outcomes of acute renal failure: a prospective randomized trial. Lancet 2000;356:26-30. [PubMed: 10892761]

65. Schiffl H, Lang S, Fischer R. Daily hemodialysis and the outcome of acute renal failure. N Engl J Med 2002;346:305-310. [PubMed: 11821506]

66. Liu KD, Himmelfarb J, Paganini E, et al. Timing of Initiation of Dialysis in Critically Ill Patients with Acute Kidney Injury. Clin J Am Soc Nephrol September 1;2006 1(5):915-919. [PubMed: 17699307]

67. Seabra VF, Balk EM, Liangos O, Sosa MA, Cendoroglo M, Jaber BL. Timing of renal replacement therapy initiation in acute renal failure: a meta-analysis. Am J Kidney Dis Aug;2008 52(2):272-284. [PubMed: 18562058]

68. Fontana RJ. Acute liver failure including acetaminophen overdose. Med Clin North Am Jul;2008 92 (4):761-794. viii. [PubMed: 18570942]

69. Auzinger G, Wendon J. Intensive care management of acute liver failure. Curr Opin Crit Care Apr; 2008 14(2):179-188. [PubMed: 18388681] 
70. Humphreys BD, Forman JP, Zandi-Nejad K, Bazari H, Seifter J, Magee CC. Acetaminophen-induced anion gap metabolic acidosis and 5-oxoprolinuria (pyroglutamic aciduria) acquired in hospital. Am J Kidney Dis Jul;2005 46(1):143-146. [PubMed: 15983968]

71. Kulig, K. Aspirin intoxication. In: Parsons, P.; Wiener-Kronish, J., editors. Critical Care Secrets. Vol. 4. Philadelphia, PA: Mosby Elsevier; 2007. p. 515-518.

72. Megarbane B, Borron SW, Baud FJ. Current recommendations for treatment of severe toxic alcohol poisonings. Intensive Care Med Feb;2005 31(2):189-195. [PubMed: 15627163]

73. Sivilotti M, Winchester J. Methanol and ethylene glycol poisoning. Up to Date.

74. Okusa MD, Crystal LJ. Clinical manifestations and management of acute lithium intoxication. Am J Med Oct;1994 97(4):383-389. [PubMed: 7942943]

75. Chu J, Stolbach A. Metformin Poisoning. Up To Date October;2008 16(3):2008.

76. Kam PC, Cardone D. Propofol infusion syndrome. Anaesthesia Jul;2007 62(7):690-701. [PubMed: 17567345]

77. Palmer BF. Hyponatremia in patients with central nervous system disease: SIADH versus CSW. Trends Endocrinol Metab May-Jun;2003 14(4):182-187. [PubMed: 12714279] 
Table 1

Summary of vasopressor and inotropic agents

\begin{tabular}{|c|c|}
\hline Vasopressors & Comments \\
\hline \multicolumn{2}{|l|}{ Alpha agonists } \\
\hline Phenylephrine (neosynephrine) & High doses can be associated with reflex bradycardia \\
\hline \multicolumn{2}{|l|}{ Mixed alpha/beta agonists } \\
\hline Norepinephrine (levophed) & Causes less tachycardia than epinephrine \\
\hline \multicolumn{2}{|l|}{ Epinephrine } \\
\hline \multicolumn{2}{|l|}{ Dopamine agonists } \\
\hline Dopamine & Like epinephrine, associated with significant tachycardia \\
\hline \multicolumn{2}{|l|}{ Other } \\
\hline Vasopressin & Increases vascular smooth muscle receptor tone via $\mathrm{V} 1$ receptor \\
\hline \multicolumn{2}{|l|}{ Inotropes } \\
\hline \multicolumn{2}{|l|}{ Beta agonists } \\
\hline Dobutamine & Use can be associated with hypotension \\
\hline \multicolumn{2}{|l|}{ Phosphodiesterase inhibitors } \\
\hline \multicolumn{2}{|l|}{ Milrinone } \\
\hline Amrinone & \\
\hline
\end{tabular}

